\title{
RESULTS OF THE EDITORIAL PROCESS 1997-2006
}

The editorial process at De Economist is a co-operative effort between the editorial board and the managing editor, who is the editorial board's executive member. Papers are received at the Amsterdam office and distributed to two appropriate co-editors, who are then in charge of initiating the refereeing process. The referees make a recommendation for or against publication to the managing editor, who is ultimately in charge of the final decision.

As the table below indicates, in the years 1997-2006 the editorial process resulted in an average rejection rate of $60 \%$. Note that the final figure for the 2006 rejection rate may change somewhat as for a number of submissions the refereeing process has not yet been completed. Communications (shorter papers) and special issue articles are not included in the figures.

TABLE - MANUSCRIPTS SUBMITTED AND REJECTED FOR PUBLICATION

\begin{tabular}{lllll}
\hline Year & Submitted (1) & Rejected (2) & $\begin{array}{l}\text { Annual rejection } \\
\text { rate (2):(1) }\end{array}$ & $\begin{array}{l}\text { Duration referee } \\
\text { process } \\
\text { (in months) }\end{array}$ \\
\hline 1997 & 30 & 16 & 0.53 & 3.0 \\
1998 & 35 & 21 & 0.60 & 2.4 \\
1999 & 34 & 23 & 0.68 & 3.7 \\
2000 & 26 & 18 & 0.69 & 3.1 \\
2001 & 29 & 15 & 0.52 & 3.0 \\
2002 & 26 & 18 & 0.69 & 2.7 \\
2003 & 28 & 14 & 0.46 & 3.1 \\
2004 & 43 & 25 & 0.58 & 2.6 \\
2005 & 27 & 14 & 0.52 & 2.6 \\
$2006^{*}$ & 27 & 19 & 0.70 & 1.8 \\
$1997-2006$ & 305 & Total & Average & 2.8 \\
\hline
\end{tabular}

* Preliminary, based on information up to and including 31 October 2006.

The duration of the refereeing process relates to the number of months passing between the first submission of the manuscript and the receipt by the authors of the referee reports and the editorial board's accompanying judgement. In the 10-year period under consideration, the average duration has been slightly less than 3 months. In 2006 further efforts to reduce the length of the refereeing process have resulted in an average duration of 1.8 months. 